\title{
Impact of Gut Microbiome Lactobacillus spp. in Brain Function and its Medicament towards Alzheimer's Disease Pathogenesis
}

\author{
Shani Kunjamma John, Vani Chandrapragasam* (D) and Pinaki Dey ${ }^{(D)}$ \\ Department of Biotechnology, Karunya Institute of Technology and Sciences, Karunya Nagar, \\ Coimbatore - 641 114, Tamil Nadu, India.
}

\begin{abstract}
Alzheimer's disease is neurodegenerative dementia which has significant health complications in the old age group. An imbalance in gut microbiota can influence to cause several diseases like chronic disorders, depression, type II diabetics, and neurological disorders like AD. Aging is one of the major causes of the development of neurodegenerative disease due to the decreasing levels of neurotransmitters, oxidative stress, chronic inflammation, and apoptosis. These harmful effects of aging can be prevented by probiotics usage. The gut-microbiota is capable to control the brain function through the gut-brain axis. Lactobacillus strains are considered as beneficial microorganism because of its importance of the maintenance in healthy intestinal microflora, immunomodulation, and intestinal pathogenic intervention. They have diverse applications in the medical field with properties like antioxidant, anticancer, anti-inflammatory, anti-proliferative, anti-obesity, and anti-diabetic activities. Probiotic supplementation with Lactobacillus strains shows an optimistic trend to use it as a significant therapy for cognitive symptoms. This review article put forwards the significance of the gut-brain axis and the contribution of Lactobacillus strains as a probiotic supplement and its therapeutic innovations for future aspects and the limitation to treat AD-related pathogenesis are briefly elucidated.
\end{abstract}

Keywords: Alzheimer's disease, neurodegenerative disease, Lactobacillus strains, dementia, gastrointestinal tract, gut-microbiota, gut-brain axis

*Correspondence: vani@karunya.edu; +91 9842215562

(Received: October 03, 2020; accepted: June 09, 2021)

Citation: John SK, Chandrapragasam V, Dey P. Impact of Gut Microbiome Lactobacillus spp. in Brain Function and its Medicament towards Alzheimer's Disease Pathogenesis. J Pure Appl Microbiol. 2021; 15(3):1029-1041. doi: 10.22207/JPAM.15.3.02

C The Author(s) 2021. Open Access. This article is distributed under the terms of the Creative Commons Attribution 4.0 International License which permits unrestricted use, sharing, distribution, and reproduction in any medium, provided you give appropriate credit to the original author(s) and the source, provide a link to the Creative Commons license, and indicate if changes were made. 


\section{INTRODUCTION}

Alzheimer's disease (AD) is a highly prevalent neurodegenerative disease in the aged group of people and nearly 44 million of the world population have AD associated dementia and estimated to be raised as 4 million in India and 5.3 million in the United States respectively ${ }^{1}$. It is a progressive, neurodegenerative ailment, a beginning of neurological decline, and stands to be an extreme and inevitably a life-threatening disease unless the death is intervened by another cause $^{2}$. AD mostly affects the parts of the brain related with higher mental capacities, explicitly the neocortex and hippocampus ${ }^{3}$.

The etiology of $A D$ is not completely perceived due to the multifactorial mechanisms underlying the disease. There are many factors which have been linked to the development and progression of AD which includes aging, cholinergic deficit, extracellular deposition of amyloid- $\beta$ protein, formed from amyloid precursor protein (APP), intracellular deposition of hyperphosphorylated tau as neurofibrillary tangles ${ }^{4}$, oxidative stress, loss of neuronal synapses and pyramidal neurons $s^{5,6}$. Among these factors, the cholinergic deficit, extracellular deposition of amyloid- $\beta$ protein, intracellular deposition of tau as neurofibrillary tangles, and oxidative stress are considered to play a significant part in $A D$ pathogenesis?.

In cholinergic deficit, the damage of cholinergic neurons happens due to the decrease of neurotransmitter like acetylcholine ${ }^{8}$, an important neurotransmitter involved in critical physiological processing of the brain will get hydrolysed by the acetylcholinesterase in the synaptic cleft, an essential reaction to allow the cholinergic neurons into its resting state. The level of acetylcholine can be maintained by using an acetylcholinesterase inhibitor is used as the treatment for $A D^{7}$.

The extracellular accumulation of amyloid- $\beta$ protein is formed by the $\beta$ pathway due to the hydrolysis of amyloid precursor protein (APP) by $\beta$-secretase (BACE1) and then by $\gamma$-secretase results in the development of insoluble $A \beta$ plagues ${ }^{7}$. $A \beta$ plagues are the potential target for $A D$ due to its pathological feature of severe neuronal loss. The treatment strategy to reduce the $A \beta$ production is by targeting on $\beta$ - and $\gamma$-secretase but causes serious side effects like blindness and large catalytic pocket ${ }^{7,9}$.

The tau is a microtubule-binding protein that helps in stabilizing and providing flexibility to the microtubules ${ }^{10}$. In pathological condition, the tau will get disintegrated from the microtubules and forms tau aggregations causing intracellular deposition of neurofibrillary tangles causes impairment in neuronal axons and therefore causes neurodegeneration ${ }^{7}$. Due to the incomplete understanding of $A D$, the tau-targeted treatment stays challenging ${ }^{7}$. oxidative stress is another significant factor of $A D$ pathogenesis brought about by the imbalance between Reactive Oxygen species (ROS) production and antioxidants levels making harm to the cells by excessive production of ROS ${ }^{11}$.

Based on different strategies, different drugs are used for the treatment of $A D$. which includes $A \beta$ plagues inhibitors (Tramiprosate and ALZ-801), anti-tau (EpoD), anti-inflammatory (NSAID) and cholinergic enhancement drug (Donepezil, Galantamine, Rivastigmine, and Tacrine) which inhibits the acetylcholinesterase (AChE) ${ }^{12,13}$ but these drugs can cause serious side effects like nausea, vomiting, muscle cramps, increased bowel movement frequencies, loss of appetite, dizziness, confusion, constipation ${ }^{14}$.

Various studies showed that the loss of biodiversity in the gastrointestinal tract of humans can lead to AD. The gut microbiota can maintain the homeostasis of the brain by producing neurotransmitters, nerve signals, and metabolites transmitted along the gut-brain axis ${ }^{15}$. Human lifestyle changes contributed a depletion in gut microbiota which could lead to a high risk of $A D$ pathogenesis ${ }^{15}$. So, an alteration in gut microbiota through a probiotic supplementation with beneficial microorganisms could reduce the risk of $A D$ pathogenesis and also side effects associated with the AD drugs.

\section{The Gut microbiota and the Gut-Brain Axis}

The gut microbiota consists of numerous bacterial species dwelling inside the gastrointestinal tract (GIT) existing as symbionts with the human hos $\mathrm{t}^{16}$ and is believed to play an essential role in physiology ${ }^{17,18}$. A $51 \%$ of gut microbiota are belonging to the Firmicutes phyla comprising the groups of Clostridium coccoides and Clostridium leptum and the most acknowledged Lactobacillus 
genera and $48 \%$ consists of the Bacteroidetes phyla comprising well recognized genera of Prevotella and Bacteroides ${ }^{19,20}$. The remaining $1 \%$ of microbiota is the less-known phyla, comprising Proteobacteria, Actinobacteria, Bifidobacteria, Fusobacteria, Spirochaetes, Verrucomicrobia, and Lentispaerae ${ }^{19,21}$.

The gut microbiota got recognition due to its connectedness to the body parts remarkably the brain. The GIT is connected with the Central nervous system (CNS) through a signaling pathway of networks including the autonomic, immune systems, neuroendocrine, bacterial metabolites, and neuromodulatory molecules are collectively called as the "gut-brain axis"19,22,23. The regulatory factors are mainly common in between enteric nervous system (ENS) and $\mathrm{CNS}^{19,24}$.

The microbiota and intestinal enterochromaffin (EC) cells secreted hormones and metabolites cross with several biochemical pathways influencing the CNS processing creating a way to communicate between the external environment in link with the gut microbiota and brain $^{19}$. The enteric nervous system formed by millions of nerves end in the GIT mucosa, helps to control the functions of the intestine and communicates with the brain through the nerve vagus and is responsible for the transmission of signals from the brain to GIT through the autonomic nervous system ${ }^{23}$. Studies suggest that an imbalance in the gut microbiota can influence the progression of neurological disorder and can initiate disease onset and also collapses the permeability of the intestine which leads to inflammatory conditions in both gut and brain, because of the proinflammatory cytokines which can enter into the bloodstream and reach the brain $^{19,25,26}$. Evidence suggests that the importance of inflammation should not be underrated, since it plays a critical role in various chronic disorders, like type II diabetes ${ }^{27}, A D^{28}$, and depression ${ }^{23,29}$.

\section{The genus lactobacillus}

The lactobacilli are Gram-positive, rods or coccobacilli non-spore formers, strict fermentative, aero-tolerant, or anaerobic with complex nutritional requirements like carbohydrates, amino acids, peptides, fatty acid esters, salts, nucleic acid derivatives, and vitamin ${ }^{30}$. Lactobacilli are either homofermentative (yielding lactic acid more than $85 \%$ ) or heterofermentative (yielding lactic acid, carbon dioxide, and ethanol/acetic acid) depends upon a carbon source as glucose $\mathrm{e}^{30}$. The strains of Lactobacillus are referred to as safe consumption bacteria because of their efficiency in gut defense mechanisms $\mathrm{s}^{31}$. Lactobacillus is a genuine member of lactic acid bacteria (LAB) and other genera includes Streptococcus, Pediococcus, Lactococcus, Leuconostoc, Bifidobacterium, Carnobacterium, Enterococcus and Sporolactobacillus ${ }^{32}$.

A probiotic is a supplementary diet consist of beneficial living microorganisms which is found as normal flora with little or no pathogenicity ${ }^{33,34}$. These probiotics are believed to have an effect on preventing or treating diseases like gastrointestinal sickness, diarrhoea, irritatable bowel syndrome, and inflammatory bowel disease $(\mathrm{IBD})^{35}$, and also possess anticancer, antioxidant, anti-obesity, antidiabetic, and antihyperlipidemic activities ${ }^{1}$. Using of Lactobacilli as a probiotic strain have a long history of safe use because of its normal inhabit in human and animal $\mathrm{GIT}^{36}$ and also considered as a beneficial microorganism because of its roles in immunomodulation, enteric pathogenic intervention, and healthy intestinal microflora maintenance ${ }^{37}$. Due to the attractiveness of "all-natural" products to treat diseases, Lactobacillus sp. (Table 1) supplemented products received popularity ${ }^{35}$.

\section{Lactobacillus sp. studies in Alzheimer's disease}

The gut microbiota's contribution to AD pathogenesis is well studied in human and animal models. Most of the studies on probiotics were associated with its effects on oral bacteriotherapy in numerous neurological diseases and function, and only a few examines have been done to find the relationship between probiotic treatment and the mechanisms connected with $A D^{48}$. The scientists have shown the benefits of probiotics to improve cognitive impairment in humans. The probiotics are hypothesized to be a cognition booster because of its two-way communication between gut microbiota, the GIT, and the brain through the immune system, nervous system, and hormones ${ }^{49}$. The contribution of Lactobacillus strains to the $A D$ pathogenesis is well depicted in $A D$ models (Table 2).

\section{DISCUSSION}

The relationship between the brain and the gut is a rapidly emerging field of study due to 


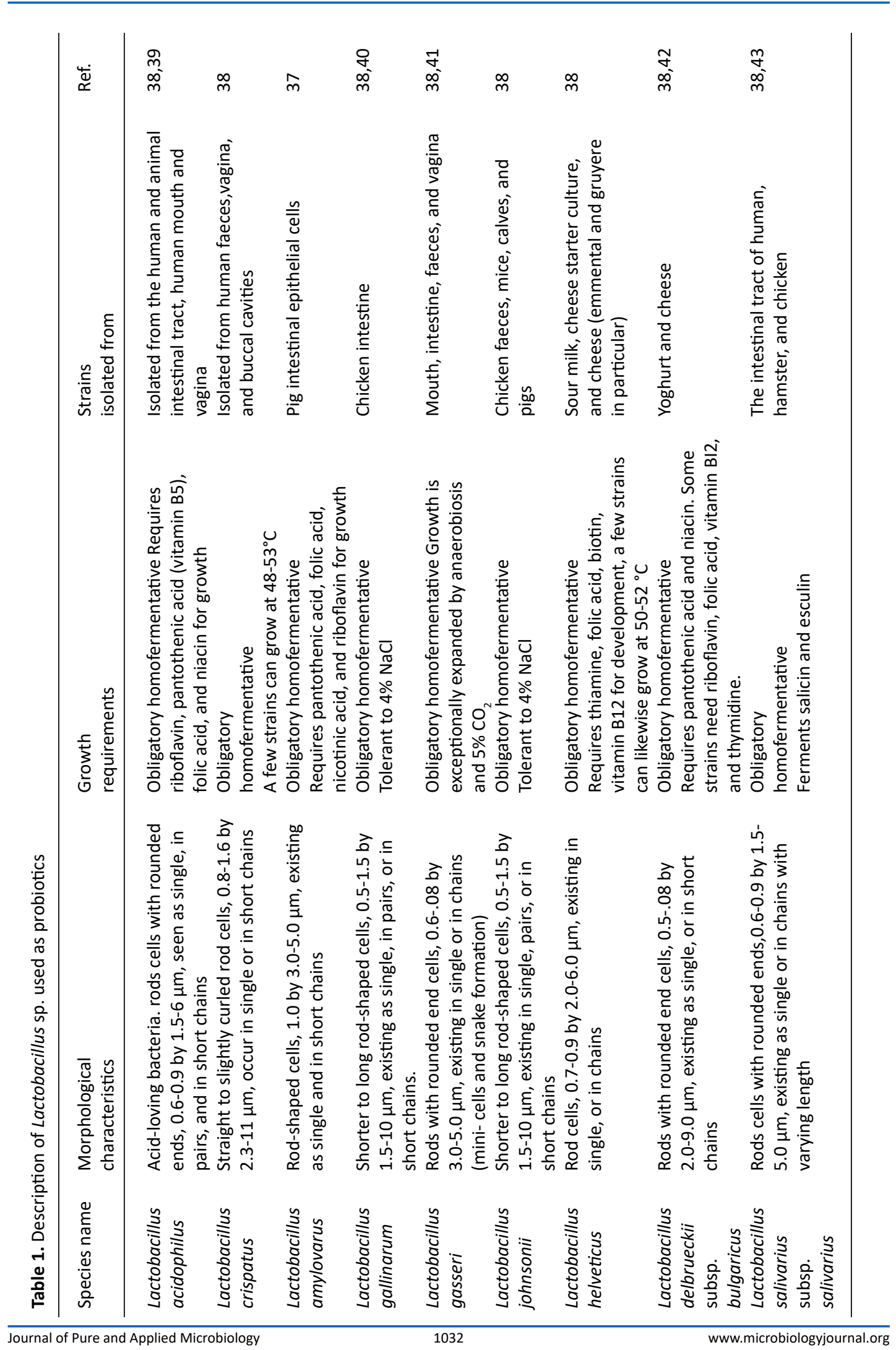




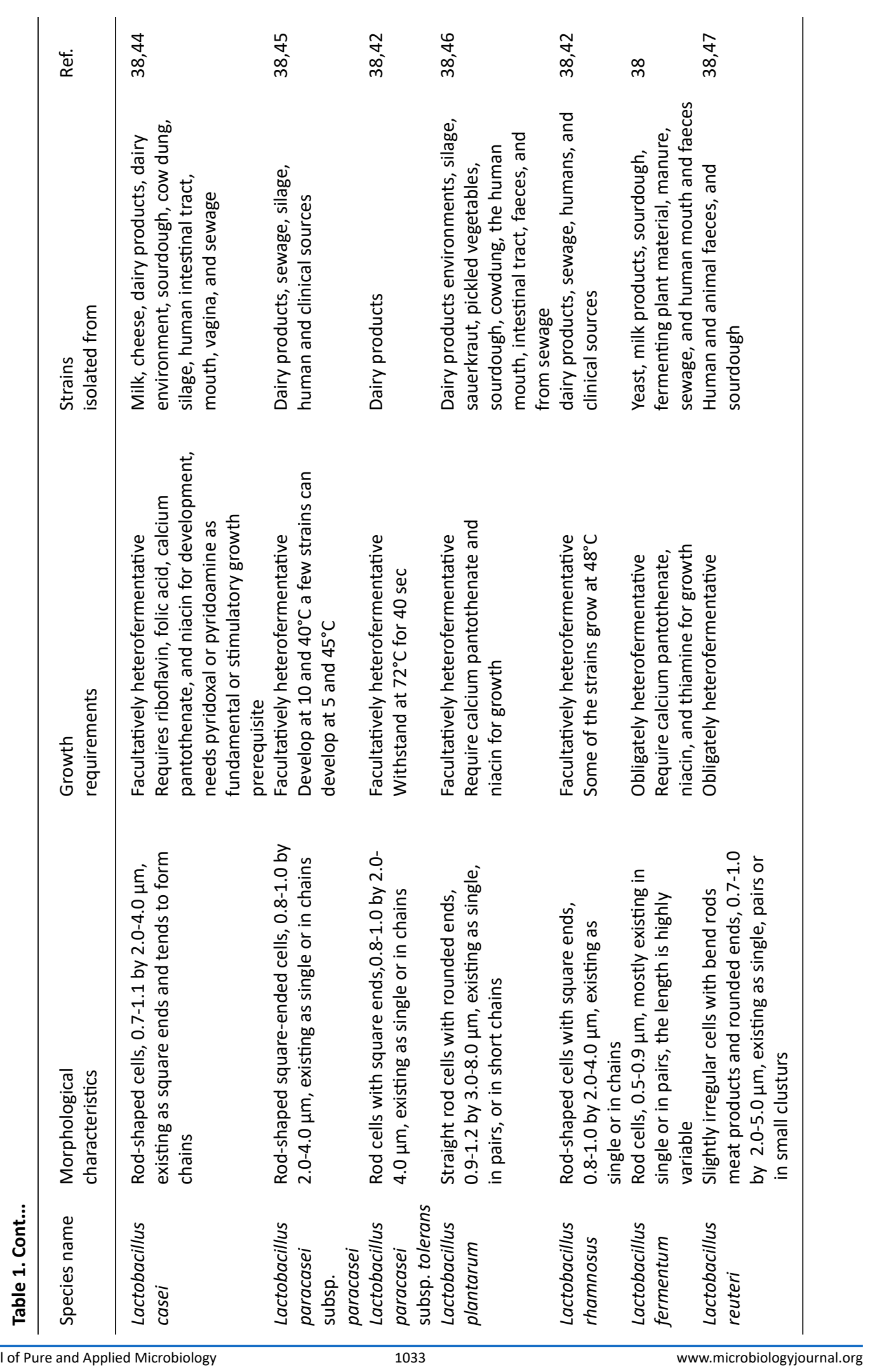




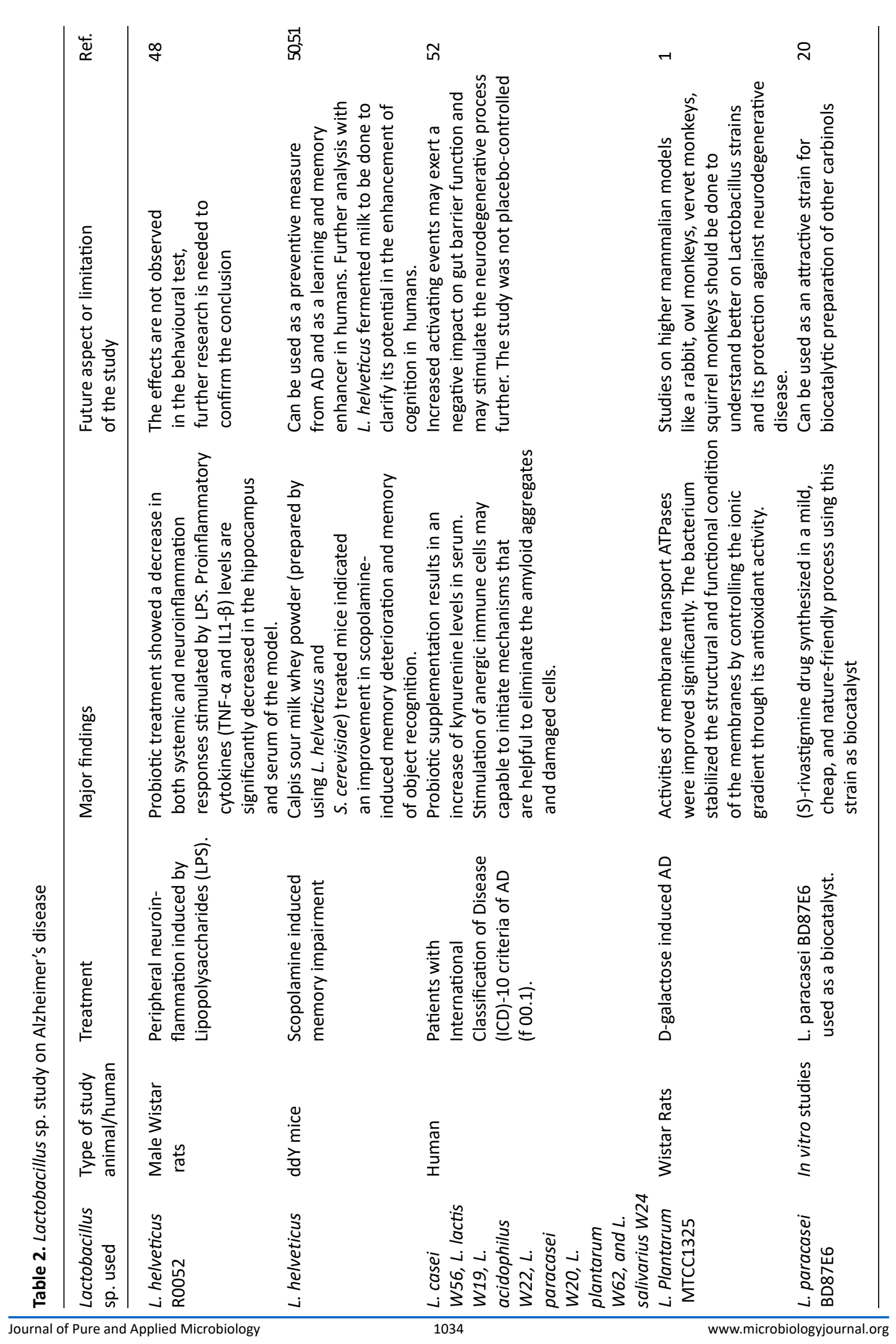




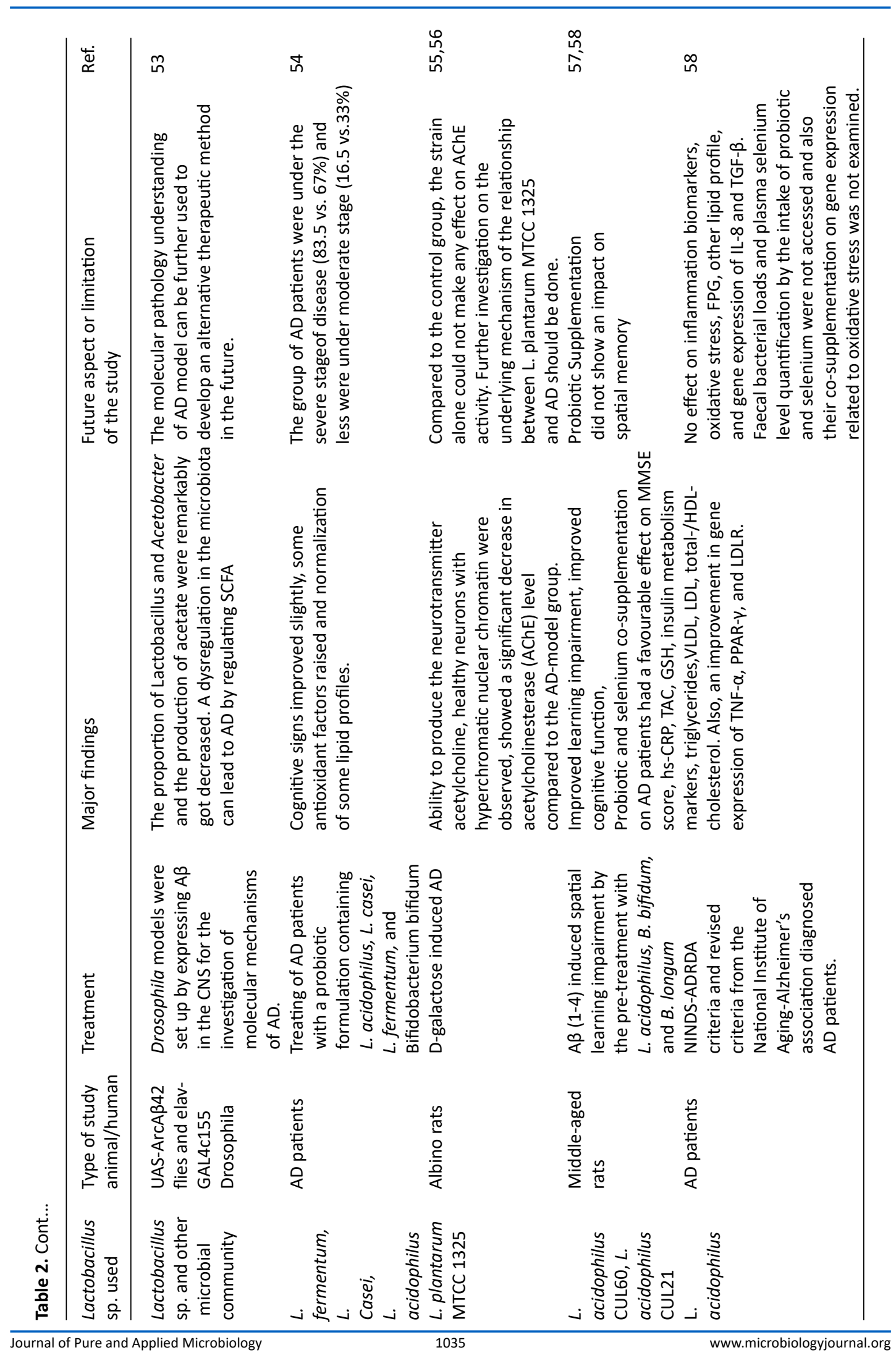




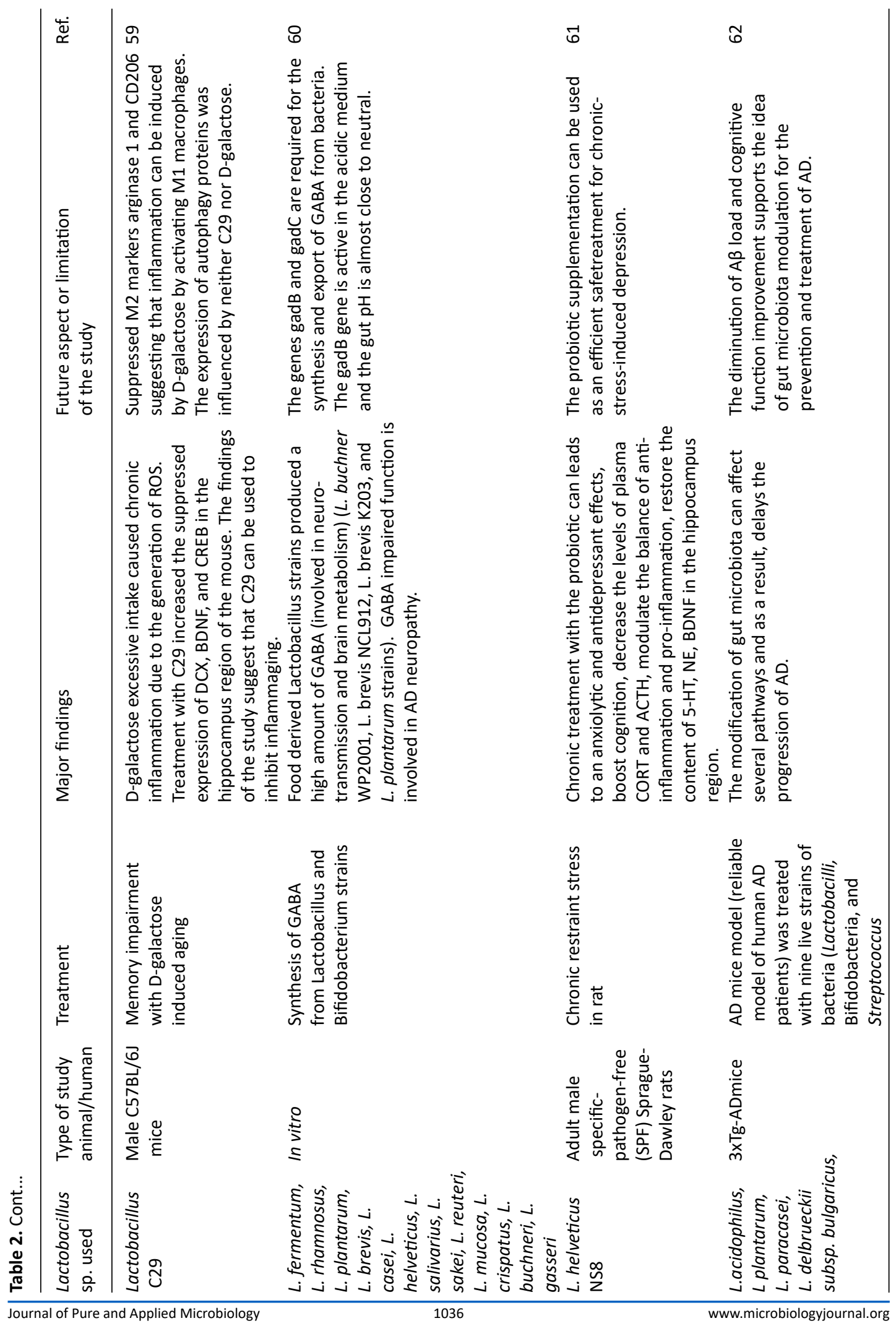




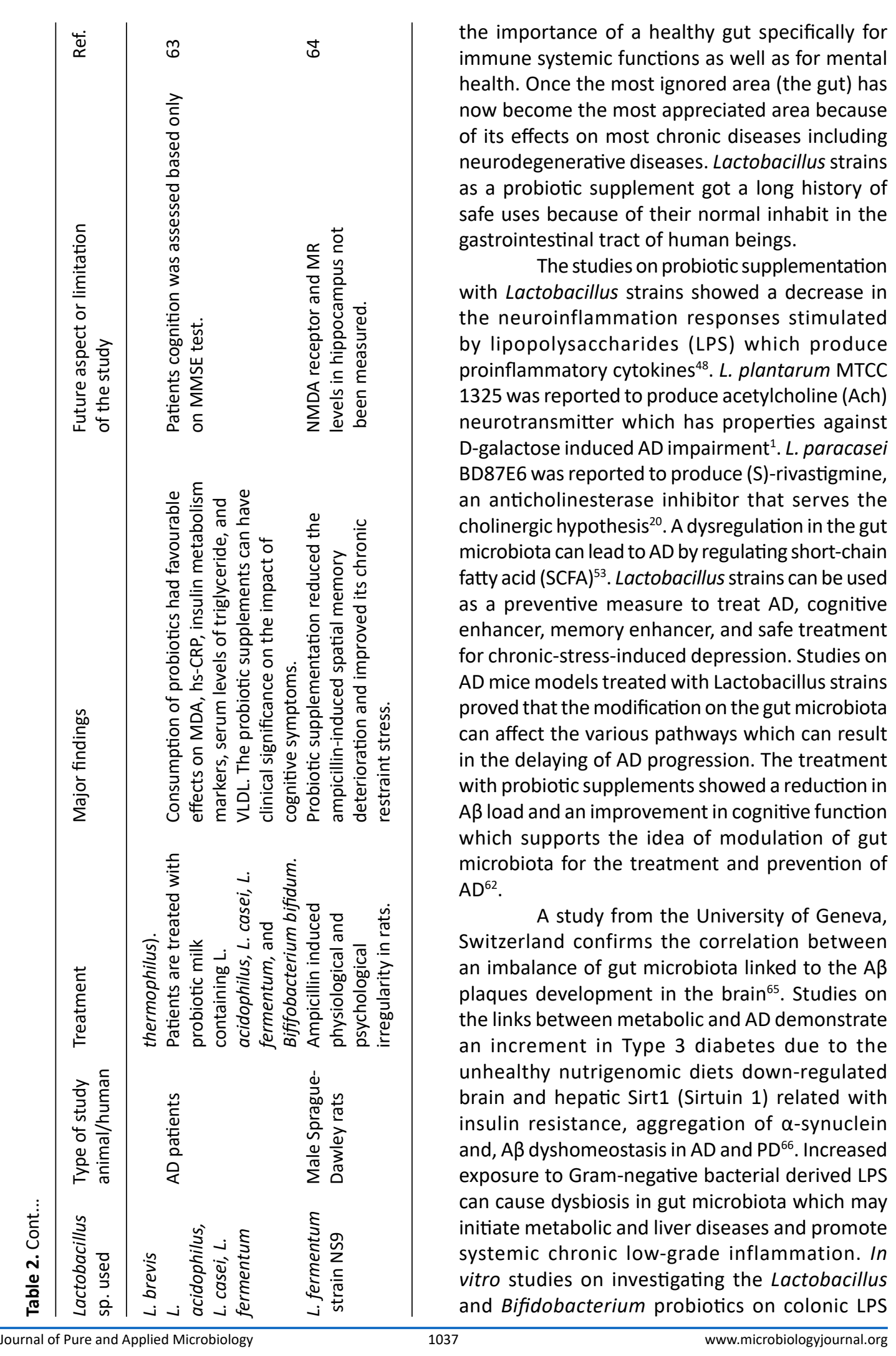


and inflammatory cytokine concentrations using human colonic microbiota models uncovered that the particular probiotic strains can diminish the concentrations of colonic LPS, which may further reduce the secretion of inflammatory cytokines in macrophage cells ${ }^{67}$. LPS alters the cell phospholipid dynamics associated with the recruitment of the $A \beta$ peptide with the advancement of toxic $A \beta$ oligomers. With the induction of a neuroinflammatory response, LPS can act on Blood-Brain Barrier (BBB) with BBB disruption or through receptors ${ }^{68}$. Through the inflammatory process, the bacterial LPS corrupts asterocyte which thus delays $A \beta$ clearance in the brain with an increased amyloid plaque formation in different networks related to excessive feeding and abnormal liver metabolism ${ }^{69}$. Researchers have been now recognized that the gene Sirt 1 to be defective and has been linked to genetic disease, non-alcoholic fatty liver disease (NAFLD), diabetics, and neurodegenerative diseases and the bacterial LPS may act as a competitive inhibitor to Sirt 1 with glucose and cholesterol toxicity to different cells and tissues ${ }^{70}$. To reactivate Sirt 1 and to improve drug-induced toxicity nutritional diets are required. For early identification of $A D$, researchers are working to identify the specific bacterial strains that produce inflammatory LPS and short-chain fatty acids (SCFAs). Understanding these underlying factors may give a new point of view on novel therapeutic strategies for $A D$ and pathologies.

\section{CONCLUSION}

Biotherapy with Lactobacillus strains shows an enormous ability to treat against ADrelated pathogenesis. Thus, Modulation of the gut with a personalized diet can become a treatment for various disorders including AD with decreased or no side effects. Further research to confirm the gut-microbiota and related linkages to the gutbrain axis are required to completely understand the scope of probiotics to treat these impaired diseases with a good safety profile. Researchers have been identified the inflammatory molecules LPS, from bacteria been linked to $A D$ and chronic gut inflammation, and SCFAs. The increased degrees of LPS are identified with chronic diseases such as NAFLD, diabetics, obesity, and neurodegenerative disease. The interest in probiotics treatments for $A D$ is quite compelling with importance to its interaction with LPS. LPS is associated with the aggregation of $A \beta$ with impacts on nuclear and cell receptors prompts to neurotoxicity and $A \beta$ plaque formation. In future researchers can contribute to the perspective of probiotic therapy with Lactobacillus strains and interaction with LPS to prevent $A \beta$ aggregation and neurodegeneration as a safe and effective therapy.

\section{ACKNOWLEDGMENTS}

We would like to thank the Department of Biotechnology, Karunya Institute of Technology and Sciences.

\section{CONFLICT OF INTEREST}

The author declares that their is no conflict of interest.

\section{AUTHORS' CONTRIBUTION}

All authors listed have made a substantial, direct and intellectual contribution to the work, and approved it for publication.

\section{FUNDING}

This research was supported by UGCMaulana Azad Fellowship, grant number F117.1/2016-17/MANF-2015-17-KER-70961.

\section{DATA AVAILABILITY}

All datasets generated or analysed during this study are included in the manuscript.

\section{ETHICS STATEMENT}

This article does not contain any studies with human participants or animals performed by any of the authors.

\section{REFERENCES}

1. Mallikarjuna N, Praveen K, Yellamma K. Role of Lactobacillus plantarum MTCC1325 in membranebound transport ATPases system in Alzheimer's disease-induced rat brain. Bioimpacts. 2016;6(4):203209. doi:10.15171/bi.2016.27

2. Barber RC. The Genetics of Alzheimer's Disease. Scientifica. 2012;2012:246210. doi: 10.6064/2012/246210

3. Francis PT, Palmer AM, Snape M, Wilcock GK. The cholinergic hypothesis of Alzheimer's disease: a review of progress. I Neurol Neurosurg Psychiatry. 1999;66(2):137-147. doi:10.1136/jnnp.66.2.137

4. Liu PP, Xie Y, Meng XY, Kang JS. History and progress of 
hypotheses and clinical trials for Alzheimer's disease. Signal Transduct Target Ther. 2019;4(1):29. doi: 10.1038/s41392-019-0063-8

5. Olasehinde TA, Olaniran AO, Okoh Al. Macroalgae as a Valuable Source of Naturally Occurring Bioactive Compounds for the Treatment of Alzheimer's Disease. Mar Drugs. 2019;17(11):609. doi: 10.3390/ md17110609

6. Subash S, Essa MM, Al-Asmi A, Al-Adawi S, Vaishnav R. Chronic Dietary Supplementation of $4 \%$ Figs on the Modification of Oxidative Stress in Alzheimer's Disease Transgenic Mouse Model. BioMed Research Int. 2014;2014:546357. doi: 10.1155/2014/546357

7. Du X, Wang X, Geng M. Alzheimer's disease hypothesis and related therapies. Translational Neurodegeneration. 2018;7(1):2. doi:10.1186/s40035018-0107-y

8. Teles AP, Takahashi JA. Paecilomide, a new acetylcholinesterase inhibitor from Paecilomyces lilacinus. Microbiol Res. 2013;168(4):204-210. doi: 10.1016/j.micres.2012.11.007

9. Klaver DW, Wilce MCJ, Cui $\mathrm{H}$, et al. Is BACE1 a suitable therapeutic target for the treatment of Alzheimer's disease? Current strategies and future directions. Biological Chemistry. 2010;391(8):849-859. doi:10.1515/bc.2010.089

10. What is Tau Protein? Accessed September 16, 2020. https://healthfully.com/466916-what-is-tau-protein. $\mathrm{html}$

11. Gandhi S, Abramov AY. Mechanism of Oxidative Stress in Neurodegeneration. Oxid Med Cell Longev. 2012;2012:428010. doi: 10.1155/2012/428010

12. Pan $\mathrm{H}$, Zhang J, Wang $\mathrm{Y}$, et al. Linarin improves the dyskinesia recovery in Alzheimer's disease zebrafish by inhibiting the acetylcholinesterase activity. Life Sciences. 2019;222:112-116. doi:10.1016/j. Ifs.2019.02.046

13. Benek O, Korabecny J, Soukup O. A Perspective on Multi-target Drugs for Alzheimer's Disease. Trends Pharmacol Sci. 2020;41(7):434-445. doi: 10.1016/j. tips.2020.04.008

14. FDA-approved-treatments-alzheimers-ts.pdf. Accessed September 16, 2020. https://alz.org/media/ Documents/fda-approved-treatments-alzheimers-ts. pdf

15. Fox M, Knorr DA, Haptonstall KM. Alzheimer's disease and symbiotic microbiota: an evolutionary medicine perspective. Ann NY Acad Sci. 2019;1449(1):3-24. doi:10.1111/nyas.14129

16. Qin J, Li R, Raes J, et al. A human gut microbial gene catalogue established by metagenomic sequencing. Nature. 2010;464(7285):59-65. doi:10.1038/ nature08821

17. Gill SR, Pop M, Deboy RT, et al. Metagenomic analysis of the human distal gut microbiome. Science. 2006;312(5778):1355-1359. doi:10.1126/ science. 1124234

18. Kim N, Yun M, Oh YJ, Choi H-J. Mind-altering with the gut: Modulation of the gut-brain axis with probiotics. J Microbiol. 2018;56(3):172-182. doi:10.1007/s12275018-8032-4

19. Westfall S, Lomis N, Kahouli I, Dia SY, Singh SP, Prakash
S. Microbiome, probiotics and neurodegenerative diseases: deciphering the gut brain axis. Cell Mol Life Sci. 2017;74(20):3769-3787. doi:10.1007/s00018-0172550-9

20. Oksuz S, Sahin E, Dertli E. Synthesis of Enantiomerically Enriched Drug Precursors by Lactobacillus paracasei BD87E6 as a Biocatalyst. Chemistry \& Biodiversity. 2018;15(6):e1800028. doi:10.1002/cbdv.201800028

21. Stojanović MR, Smidt H, Vos WMD. Diversity of the human gastrointestinal tract microbiota revisited. Environmental Microbiology. 2007;9(9):2125-2136. doi:10.1111/j.1462-2920.2007.01369.x

22. Quigley EMM. Microbiota-Brain-Gut Axis and Neurodegenerative Diseases. Curr Neurol Neurosci Rep. 2017;17(12):94. doi:10.1007/s11910-017-0802-6

23. Luca M, Di Mauro M, Di Mauro M, Luca A. Gut Microbiota in Alzheimer's Disease, Depression, and Type 2 Diabetes Mellitus: The Role of Oxidative Stress. Oxid Med Cell Longev. 2019;2019:4730539. doi:10.1155/2019/4730539

24. Burns AJ. Migration of neural crest-derived enteric nervous system precursor cells to and within the gastrointestinal tract. Int J Dev Biol. 2005;49(2-3):143150. doi:10.1387/ijdb.041935ab

25. Catanzaro R, Anzalone M, Calabrese $F$, et al. The gut microbiota and its correlations with the central nervous system disorders. Panminerva Med. 2014;57(3):127-143.

26. Kelly JR, Kennedy PJ, Cryan JF, Dinan TG, Clarke G, Hyland NP. Breaking Down the Barriers: The Gut Microbiome, Intestinal Permeability and Stressrelated Psychiatric Disorders. Front Cell Neurosci. 2015;9:392. Accessed September 16, 2020. doi: 10.3389/fncel.2015.00392

27. Xu Y, Zhou H, Zhu Q. The Impact of MicrobiotaGut-Brain Axis on Diabetic Cognition Impairment. Front Aging Neurosci. 2017;9:106. doi:10.3389/ fnagi.2017.00106

28. Luca M, Luca A, Calandra C. The Role of Oxidative Damage in the Pathogenesis and Progression of Alzheimer's Disease and Vascular Dementia. Oxid Med Cell Longev.2015;2015:504678. doi: $10.1155 / 2015 / 504678$

29. Kim JM, Stewart R, Kim JW, et al. Changes in pro-inflammatory cytokine levels and late-life depression: A two year population based longitudinal study. Psychoneuroendocrinology. 2018;90:85-91. doi:10.1016/j.psyneuen.2018.02.006

30. Hammes WP, Vogel RF. The genus Lactobacillus. In: Wood BJB, Holzapfel WH, eds. The Genera of Lactic Acid Bacteria. The Lactic Acid Bacteria. Springer US. 1995:19-54. doi:10.1007/978-1-4615-5817-0_3

31. Arasu MV, Al-Dhabi NA, Ilavenil S, Choi KC, Srigopalram S. In vitro importance of probiotic Lactobacillus plantarum related to medical field. Saudi J Biol Sci. 2016;23(1, Suppl):S6-S10. doi:10.1016/j. sjbs.2015.09.022

32. Wood BJB. The Lactic Acid Bacteria: Volume 1: The Lactic Acid Bacteria in Health and Disease. Springer Science \& Business Media; 2012.

33. Alvarez-Olmos MI, Oberhelman RA. Probiotic Agents and Infectious Diseases: A Modern Perspective on a 
Traditional Therapy. Clin Infect Dis. 2001;32(11):15671576. doi:10.1086/320518

34. Salminen S, Arvilommi H. Probiotics Demonstrating Efficacy in Clinical Settings. Clin Infect Dis. 2001;32(11):1577-1578. doi:10.1086/320529

35. Slover CM, Danziger L. Lactobacillus: a Review. Clin Microbiol Newsl. 2008;30(4):23-27. doi:10.1016/j. clinmicnews.2008.01.006

36. Floch $\mathrm{MH}$, Walker WA, Guandalini $\mathrm{S}$, et al. Recommendations for probiotic use--2008. J Clin Gastroenterol. 2008;42(Suppl 2):S104-108. doi:10.1097/MCG.0b013e31816b903f

37. Kant R, Paulin L, Alatalo E, de Vos WM, Palva A. Genome Sequence of Lactobacillus amylovorus GRL1118, Isolated from Pig lleum. J Bacteriol. 2011;193(12):3147-3148. doi:10.1128/JB.00423-11

38. Wood BJB, Holzapfel WHN. The Genera of Lactic Acid Bacteria. Springer Science \& Business Media. 1995;2.

39. Altermann E, Russell WM, Azcarate-Peril MA, et al. Complete genome sequence of the probiotic lactic acid bacterium Lactobacillus acidophilus NCFM. Proc Natl Acad Sci . 2005;102(11):3906-3912. doi:10.1073/ pnas. 0409188102

40. Sun Z, Harris HMB, McCann A, et al. Expanding the biotechnology potential of lactobacilli through comparative genomics of 213 strains and associated genera. Nat Commun. 2015;6(1):8322. doi:10.1038/ ncomms9322

41. Marcotte $\mathrm{H}$, Brandsborg E, Hammarstrom L. Lactobacillus gasseri DSM 14869. Accessed September 16, 2020. https://www.uniprot.org/proteomes/ UP000217220

42. Pot B, Felis GE, Bruyne KD, et al. The genus Lactobacillus. In: Lactic Acid Bacteria. John Wiley \& Sons, Ltd; 2014:249-353. doi:10.1002/9781118655252.ch19

43. Goodfellow M, Whitman WB, Bergey DH, et al. Eds. Bergey's Manual of Systematic Bacteriology. Vol. 5: The Actinobacteria 2. Ed. Springer; 2012.

44. Makarova K, Slesarev A, Wolf $Y$, et al. Comparative genomics of the lactic acid bacteria. Proc Natl Acad Sci . 2006;103(42):15611-15616. doi:10.1073/ pnas. 0607117103

45. Collins MD, Phillips BA, Zanoni P. Deoxyribonucleic Acid Homology Studies of Lactobacillus casei, Lactobacillus paracasei sp. nov., subsp. paracasei and subsp. tolerans, and Lactobacillus rhamnosus sp. nov., comb. nov. Int J Syst Evol Microbiol. 1989;39(2):105-108. doi:10.1099/00207713-39-2-105

46. van Kranenburg R, Golic N, Bongers R, et al. Functional Analysis of Three Plasmids from Lactobacillus plantarum. AEM. 2005;71(3):1223-1230. doi:10.1128/ AEM.71.3.1223-1230.2005

47. Vos P, Garrity G, Jones D, et al. Bergey's Manual of Systematic Bacteriology: Volume 3: The Firmicutes (Bergey's Manual of Systematic Bacteriology (Springer-Verlag)). Accessed September 16, 2020. https://b-ok.asia/ book/1273128/4c6e79? redirect $=29896517$ \& region Changed $=\&$ signAll $=1$

48. Mohammadi G, Dargahi L, Peymani A, et al. The Effects of Probiotic Formulation Pretreatment (Lactobacillus helveticus R0052 and Bifidobacterium longum R0175) on a Lipopolysaccharide Rat Model. J Am Coll Nutr. 2019;38(3):209-217. doi:10.1080/07315724.2018.14 87346

49. Probiotics improve cognition in Alzheimer's patients. Science \& research news. Frontiers. 2016. Accessed September 16, 2020. https://blog.frontiersin. org/2016/11/10/probiotics-improve-cognition-inalzheimers-patients/

50. Kim B, Hong VM, Yang J, et al. A Review of Fermented Foods with Beneficial Effects on Brain and Cognitive Function. Prev Nutr Food Sci. 2016;21(4):297-309. doi:10.3746/pnf.2016.21.4.297

51. Ohsawa K, Uchida N, Ohki K, Nakamura Y, Yokogoshi H. Lactobacillus helveticus-fermented milk improves learning and memory in mice. Nutr Neurosci. 2015;18(5):232-240. doi:10.1179/147683051 $4 \mathrm{Y} .0000000122$

52. Leblhuber F, Steiner K, Schuetz B, Fuchs D, Gostner JM. Probiotic Supplementation in Patients with Alzheimer's Dementia - An Explorative Intervention Study. Current Alzheimer Research. 2018;15(12):1106-1113. doi:10.2 174/1389200219666180813144834

53. Kong $Y$, Jiang $B$, Luo $X$. Gut microbiota influences Alzheimer's disease pathogenesis by regulating acetate in Drosophila model. Future Microbiology. 2018;13(10):1117-1128. doi:10.2217/fmb-2018-0185

54. Agahi A, Hamidi GA, Daneshvar R, et al. Does Severity of Alzheimer's Disease Contribute to Its Responsiveness to Modifying Gut Microbiota? A Double Blind Clinical Trial. Front Neurol. 2018;9:662. doi:10.3389/ fneur.2018.00662

55. Stephenson M, Rowatt E. The production of acetylcholine by a strain of Lactobacillus plantarum. J Gen Microbiol. 1947;1(3):279-298. doi:10.1099/00221287-1-3-279

56. Nimgampalle M, Kuna Y. Anti-Alzheimer Properties of Probiotic, Lactobacillus plantarum MTCC 1325 in Alzheimer's Disease induced Albino Rats. J Clin Diagn Res. 2017;11(8):KC01-KC05. doi:10.7860/ JCDR/2017/26106.10428

57. RezaeiasI Z, Salami M, Sepehri G. The Effects of Probiotic Lactobacillus and Bifidobacterium Strains on Memory and Learning Behavior, Long-Term Potentiation (LTP), and Some Biochemical Parameters in $\beta$-Amyloid-Induced Rat's Model of Alzheimer's Disease. Prev Nutr Food Sci. 2019;24(3):265-273. doi:10.3746/pnf.2019.24.3.265

58. Tamtaji OR, Heidari-soureshjani R, Mirhosseini N, et al. Probiotic and selenium co-supplementation, and the effects on clinical, metabolic and genetic status in Alzheimer's disease: A randomized, double-blind, controlled trial. Clinical Nutrition. 2019;38(6):25692575. doi:10.1016/j.clnu.2018.11.034

59. Woo JY, Gu W, Kim KA, Jang SE, Han MJ, Kim $\mathrm{DH}$. Lactobacillus pentosus var. plantarum C29 ameliorates memory impairment and inflammaging in a d-galactose-induced accelerated aging mouse model. Anaerobe. 2014;27:22-26. doi:10.1016/j. anaerobe.2014.03.003

60. Yunes RA, Poluektova EU, Dyachkova MS, et al. GABA production and structure of gadB/gadC genes in Lactobacillus and Bifidobacterium strains from 
human microbiota. Anaerobe. 2016;42:197-204. doi:10.1016/j.anaerobe.2016.10.011

61. Liang $\mathrm{S}$, Wang $\mathrm{T}, \mathrm{Hu} \mathrm{X}$, et al. Administration of Lactobacillus helveticus NS8 improves behavioral, cognitive, and biochemical aberrations caused by chronic restraint stress. Neuroscience. 2015;310:561577. doi:10.1016/j.neuroscience.2015.09.033

62. Bonfili L, Cecarini V, Berardi S, et al. Microbiota modulation counteracts Alzheimer's disease progression influencing neuronal proteolysis and gut hormones plasma levels. Scientific Reports. 2017;7(1):2426. doi:10.1038/s41598-017-02587-2

63. Akbari E, Asemi Z, Daneshvar Kakhaki R, et al. Effect of Probiotic Supplementation on Cognitive Function and Metabolic Status in Alzheimer's Disease: A Randomized, Double-Blind and Controlled Trial. Front Aging Neurosci. 2016;8:256. doi:10.3389/ fnagi.2016.00256

64. Wang T, Hu X, Liang S, et al. Lactobacillus fermentum NS9 restores the antibiotic induced physiological and psychological abnormalities in rats. Beneficial Microbes. 2015;6(5):707-717. doi:10.3920/BM2014.0177

65. Marizzoni M, Cattaneo A, Mirabelli P, et al. Short-Chain Fatty Acids and Lipopolysaccharide as Mediators between Gut Dysbiosis and Amyloid Pathology in Alzheimer's Disease. J Alzheimer's Dis. 2020;78(2):683-
697. doi:10.3233/JAD-200306

66. Martins IJ. Diabetes and cholesterol dyshomeostasis involve abnormal $\alpha$-synuclein and amyloid beta transport in neurodegenerative diseases. Austin Alzheimer's Journal of Parkinson's Disease. 2015;2(1):1020. https://austinpublishinggroup.com/ aapd/fulltext/aapd-v2-id1020.php

67. Rodes L, Khan A, Paul A, et al. Effect of probiotics Lactobacillus and Bifidobacterium on gut-derived lipopolysaccharides and inflammatory cytokines: an in vitro study using a human colonic microbiota model. J Microbiol Biotechnol. 2013;23(4):518-526. doi:10.4014/jmb.1205.05018

68. Martins IJ. Bacterial lipopolysaccharides change membrane fluidity with relevance to phospholipid and amyloid beta dynamics in Alzheimer's disease. Journal of Microbial \& Biochemical Technology. 2016;8(4):322324. doi:10.4172/1948-5948.1000304

69. Martins IJ. Unhealthy Diets Determine Benign or Toxic Amyloid Beta States and Promote Brain Amyloid Beta Aggregation. Austin Journal of Clinical Neurology. 2015;2(7):1060.

70. James MI. The Future of Genomic Medicine Involves the Maintenance of Sirtuin 1 in Global Populations. IJMBOA. 2017;2(2):42-45. doi:10.15406/ ijmboa.2017.02.00013 